\title{
Membrane-Based Processes to Obtain High-Quality Water From Brewery Wastewater
}

\author{
Marc Sauchelli Toran ${ }^{1}$, Patricia Fernández Labrador ${ }^{2}$, Juan Francisco Ciriza ${ }^{2}$, \\ Yeray Asensio ${ }^{1}$, André Reigersman ${ }^{3}$, Juan Arevalo ${ }^{1}$, Frank Rogalla ${ }^{1}$ and \\ Victor M. Monsalvo ${ }^{1 *}$ \\ ${ }^{1}$ Aqualia, Departamento de Innovación y Tecnología, Av Del Camino de Santiago, Madrid, Spain, ${ }^{2}$ Mahou San Miguel, Calle Titán, \\ Madrid, Spain, ${ }^{3}$ Rood Wit Blauw Water Systems, Ambachtstraat, Almelo, Netherlands
}

Water reuse is a safe and often the least energy-intensive method of providing water from non-conventional sources in water stressed regions. Although public perception can be a challenge, water reuse is gaining acceptance. Recent advances in membrane technology

OPEN ACCESS

Edited by:

Evina Katsou,

Brunel University London, United Kingdom

Reviewed by: Henry Jonathan Tanudjaja, Nanyang Environment \& Water Research Institute, Singapore Mohammad Younas,

University of Engineering \& Technology Peshawar, Pakistan

${ }^{*}$ Correspondence: Victor M. Monsalvo victor.monsalvo@fcc.es

Specialty section: This article was submitted to Separation Processes,

a section of the journal Frontiers in Chemical Engineering

Received: 30 June 2021

Accepted: 26 August 2021 Published: 14 September 2021

Citation:

Toran MS, Labrador PF, Ciriza JF, Asensio Y, Reigersman A, Arevalo J,

Rogalla $F$ and Monsalvo VM (2021)

Membrane-Based Processes to

Obtain High-Quality Water From

Brewery Wastewater.

Front. Chem. Eng. 3:734233.

doi: 10.3389/fceng.2021.734233 allow for reclamation of wastewater through the production of high-quality treated water, including potable reuse. This study takes an in-depth evaluation of a combination of membrane-based tertiary processes for its application in reuse of brewery wastewater, and is one of the few studies that evaluates long-term membrane performance at the pilotscale. Two different advanced tertiary treatment trains were tested with secondary wastewater from a brewery wastewater treatment plant (A) ultrafiltration (UF) and reverse osmosis $(\mathrm{RO})$, and $(\mathrm{B})$ ozonation, coagulation, microfiltration with ceramic membranes (MF) and RO. Three specific criteria were used for membrane comparison: 1) pilot plant optimisation to identify ideal operating conditions, 2) Clean-In-Place (CIP) procedures to restore permeability, and 3) final water quality obtained. Both UF and MicroFiltration membranes were operated at increasing fluxes, filtration intervals and alternating phases of backwash (BW) and chemically enhanced backwash (CEB) to control fouling. Operation of polymeric UF membranes was optimized at a flux of 25-30 LMH with 15-20 min of filtration time to obtain longer production periods and avoid frequent CIP membrane cleaning procedures. Combination of ozone and coagulation with ceramic MF membranes resulted in high flux values up to $120 \mathrm{LMH}$ with CEB:BW ratios of 1:4 to 1:10. Coagulation doses of 3-6ppm were required to deal with the high concentrations of polyphenols (coagulation inhibitors) in the feed, but higher concentrations led to increasing fouling resistance of the MF membrane. Varying the ozone concentration stepwise from 0 to $25 \mathrm{mg} / \mathrm{L}$ had no noticeable effect on coagulation. The most effective cleaning strategy was found to be a combination of $2000 \mathrm{mg} / \mathrm{L} \mathrm{NaOCl}$ followed by $5 \% \mathrm{HCl}$ which enabled to recover permeability up to $400 \mathrm{LMH} \cdot \mathrm{bar}^{-1}$. Both polymeric UF and ceramic MF membranes produced effluents that fulfil the limits of the national regulatory framework for reuse in industrial services (RD 1620/2007). Coupling to the RO units in both tertiary trains led to further water polishing and an improved treated water quality.

Keywords: ceramic, membrane, wastewater reuse, desalination, brewery 


\section{INTRODUCTION}

In the overall growing context of water scarcity and deterioration in water quality, alternative methods to produce water at the lowest costs from non-conventional water sources are being intensively studied (Angelakis and Durham 2008; Hochstrat et al., 2010;2017; Ansari et al., 2017). In particular, the industrial sector is having to adapt to the increasing pressures on water resources and stricter wastewater discharge regulations by either cutting down on water consumption or by integrating water reuse in the existing wastewater treatment facilities.

The benefits of water reuse are more limited extraction from surface and ground-water sources, reduced impact of treated wastewater discharge into water bodies, and production of highquality treated water for multiple on-site applications. Further economic benefits include lower water intake costs, lower wastewater disposal fees and optimized energy efficiency of water treatment (Pankratz 2004; Vanoppen et al., 2016).

The brewery industry is a large consumer of water, and it is estimated that for every $1 \mathrm{~L}$ of beer that is brewed, around $5 \mathrm{~L}$ of water are used: mostly for the brewing, rinsing, and cooling processes. Consequently, breweries generate large amounts of wastewater, characterized by significant levels of organic substances (starch, sugars, ethanol and volatile fatty acids), that require adequate treatment before discharge into the environment. Conventional wastewater treatment in breweries consists of various physico-chemical primary treatment steps followed by secondary biological processes, such as aerobic sequencing batch reactors, up-flow anaerobic sludge blanket reactors or anaerobic membrane bioreactors (Simate et al., 2011; Werkneh et al., 2019).

Thereafter, the biologically treated wastewater can be further polished for reuse. According to Verhuelsdonk et al. (2021), reusing brewery wastewater was found to be economically viable in $77.2 \%$ of simulated cases, showing the strongest dependency on costs was wastewater disposal. The endpoint application of the reclaimed wastewater, either for irrigation, cooling, packaging or general cleaning water, defines the treatment capacity required. A wide range of technologies have been evaluated as tertiary treatment for brewery wastewater with differing results, including quenched plasma, bioreactors, microbial fuel cells and membrane processes (Meshksar, Roostaee, and Rahimpour 2020).

Membrane-based separation processes have undergone rapid development in recent years as advanced tertiary treatment systems for water reuse due to their robustness, high chemical tolerance and low energy consumption (Blandin et al., 2016; Cath et al., 2010; Attarde et al., 2017). In particular, pressure-driven membrane technologies that are widely adopted in municipal wastewater treatment have been identified for their potential use in brewery wastewater reclamation. These include: stand-alone Ultrafiltration (UF), Nanofiltration (NF) or Reverse Osmosis (RO) polymeric membranes, as well as combinations of these technologies (Van der Bruggen and Braeken 2006; Acero et al., 2010; Villa and Salgado, 2013). In one case, Götz et al. (2014) investigated the filtration performance of a UF membrane treating different brewery process water flows and highlighted the negative impact of specific cleaning agents on the UF membrane. Braeken et al. (2004), tested the efficiency of NF membranes (with pore sizes between 1 and $10 \mathrm{~nm}$ ) with biologically treated brewery wastewater. A very high removal of Chemical Oxygen Demand (COD) was reported but it was insufficient to obtain the required water quality, mainly due to the high concentration of organics present in the wastewater.

A later study that compared NF and RO processes, found that polymeric RO membranes exceeded the COD removal capacity of $\mathrm{NF}$ and retained higher fluxes when treating an ethanol-rich stream (Madaeni and Mansourpanah, 2006). In contrast, Anwar and Rahaman. (2020) concluded that both NF and RO suffered from severe membrane fouling, showing poor water recoveries below $18 \%$. In general, $\mathrm{RO}$ is coupled with other physical separation techniques or physico-chemical pre-treatment steps such as coagulation/flocculation or powdered activated carbon to enhance its performance. For example, several integrated UFRO membrane systems have been successfully installed in different types of industries with a wide range of water sources. Results from these case studies showed improvement in water quality, lower cleaning frequencies and lower operating costs than when using stand-alone RO filtration (Suárez et al., 2013). Although long-term operation of integrated membrane processes can be found in the literature, few are tested with pre-treated brewery wastewater. Therefore, there is a pressing need to explore these technologies at the pilot-scale, especially when coupled together, to evaluate their full potential for water reuse in the brewery industry.

Another membrane-based technology that is yet to be tested in the context of brewery wastewater reuse is Ceramic Micro-Filtration (MF). The cost of these membranes is rapidly decreasing with improved manufacturing and higher demand, and their application in wastewater treatment is growing (Park et al., 2015). New ceramic membranes have been recently introduced with unique advantages and properties over currently available polymeric membranes, including better backwash efficiency as the membrane can withstand high pressures and chemical pretreatment (Xing et al., 2013). Flocculation/Coagulation is effective in removing suspended particles and natural organic matter (NOM) prior to filtration. The dose of the coagulant has been found to influence the membrane filtration performance and an optimum dose exists where membrane fouling is reduced significantly (Meyn and Leiknes 2010).

Ozone also has a high reactivity with NOM and has been shown to reduce membrane fouling under appropriate operating conditions. Lehman and Liu. (2009), tested a hybrid ozonation-ceramic MF membrane system for long-term treatment of secondary wastewater and found that ozone significantly reduces membrane fouling. In addition, the resistance of ceramic MF membranes to mechanical, thermal, and chemical stress allows for more aggressive cleaning and a better recovery of membrane performance. Bhattacharya et al. (2013) investigated the dual-stage treatment of high organic load tannery wastewater with MF followed by RO and demonstrated that the product water was fit for reuse within the facility. Nonetheless, little research has been carried-out with ceramic MF systems with prior ozonation and/or coagulation, generating interest in testing this new technology at the pilotscale and particularly in the brewery industry. 


\section{UF MEMBRANE}

Pore Diameter: $0.03 \mu \mathrm{m}$

Filtration Mode: Out/In

Membrane Material: PVDF

Membrane Surface Area: $51 \mathrm{~m}^{2}$

Length: $1860 \mathrm{~mm}$

Feed Flow: $2-6.5 \mathrm{~m}^{3} / \mathrm{h}$

Max TMP: 2.1 bar

Max system pressure: 6.25 bar

Max Temperature: $40{ }^{\circ} \mathrm{C}$

Recommended Flux: 40 to $120 \mathrm{LMH}$

Max Backwash Pressure: 2.5 bar

pH: 2 - 11

Max $\mathrm{NaOCl}$ concentration: 2000 ppm

MF CERAMIC MEMBRANE

Membrane Surface Area: 1 x $0.4 \mathrm{~m}^{2}$

Treatment Capacity: 40-160 L/h

Flux Range: 100-400 LMH

Nominal Pore Size: $0.1 \mu \mathrm{m}$

Max. TMP: 2 bar

Ozone concentration at entry: $1 \mathrm{ppm}$

\section{RO MEMBRANE}

Feed Flow: $4.50 \mathrm{~m}^{3} / \mathrm{h}$

Membrane material: Polyamide

Membrane type: Spiral-Wound

Membrane length: $1,016 \mathrm{~m}$

Membrane surface area: $37 \mathrm{~m}^{2}$

No. of stages: 2

No. of membranes per stage: 2

Total Membrane surface area: $148 \mathrm{~m}^{2}$

Recovery rate: $90 \%$

Recirculation of concentrate: Yes

A

\section{RO MEMBRANE}

Spiral Wound elements: 2 elements in series

Membrane Surface Area: $2 \times 1.2 \mathrm{~m}^{2}$

Treatment Capacity: 26-28.8 L/h

Flux Range: 11-12 LMH

RO Recovery: $75 \%$

Feed Pressure: Up to 5 bar

ies

FIGURE 1 | Membrane characteristics of the two treatment trains, (A) UF + RO, (B) Ozone + Coagulation $+\mathrm{MF}+\mathrm{RO}$.

This paper provides relevant results from the long-term operation of full-scale innovative membrane-based processes for brewery wastewater recovery. The treatment capacity and water recovery performance by two different advanced tertiary treatment systems is evaluated and compared. These two systems or treatment trains consist in A) UF and RO modules in series and $\mathrm{B}$ ) ozonation, coagulation, MF with ceramic membranes and RO. Both systems are continuously fed with effluent of a full-scale brewery wastewater treatment plant (WWTP). Commercially available membranes are tested in each unit and monitored with respect to fouling propensity, flux decline and contaminant rejection. Three specific criteria are used for the evaluation: 1) optimisation of the pilot plants to determine the ideal operational conditions, 2) efficacy of Clean-In-Place (CIP) procedures to restore the permeability of the membranes and 3) the water quality produced during continuous operation relative to the wastewater reuse regulations.

\section{MATERIALS AND METHODS}

This study was carried out at the Mahou-San Miguel brewing facility located in Alovera (Spain), one of the biggest brewing plants in Europe. The pilot testing site was located in the facility's WWTP with access to secondary wastewater. On average, the brewery WWTP treats up to $250 \mathrm{~m}^{3} / \mathrm{h}$ of wastewater.

\section{Pilot Plants Description}

In this study, two different tertiary treatment trains were evaluated and compared, each using a combination of different technologies to treat secondary effluent and obtain high quality product water for reuse purposes. The treatment trains included a combination of membrane-based processes (MF, UF and RO) as well as widely used physico-chemical processes. The schematics of both tertiary treatment trains are illustrated in Figure 2.

The first treatment train consists of an initial $150 \mu \mathrm{m}$ ring filter, followed by two polymeric PVDF UF membranes in parallel and in a separate pilot plant, two RO modules in series. The UF membrane pilot unit equipped with two top tier commercial pressurized UF membranes, each with $51 \mathrm{~m}^{2}$ of membrane surface and $0.03 \mu \mathrm{m}$ nominal pore size, were operated using an out-in filtration configuration and dead-end mode. More detailed membrane characteristics are listed in Figure 1. The pilot plant was designed to reach a treatment capacity (permeate production) between 2 and $6.5 \mathrm{~m}^{3} / \mathrm{h}$ and a feed/permeate conversion of around 95\%. Permeate from the UF membrane was also stored in a backwash tank, and this water was used for the chemically enhanced backwash which is described in detail in Membrane Cleaning Protocols. The UF unit was followed by a RO pilot plant equipped with two top tier commercial RO modules each containing $2 \mathrm{RO}$ membranes with $37 \mathrm{~m}^{2}$ of surface area and able to treat up to $4.5 \mathrm{~m}^{3} / \mathrm{h}$ with a global process recovery rate of over $90 \%$.

The second tertiary treatment train consists of a security screen filter, an ozone pre-oxidation mixing tank, a coagulation tank, a ceramic membrane MF and a final RO unit. Ozone was dosed as pre-oxidation treatment to oxidize and ionize the organic compounds and maximize the coagulation efficiency, as well as minimize membrane fouling. The ozone produced from a corona discharge generator was injected into a static mixer and allowed to dissolve in the feed water in an ozone 


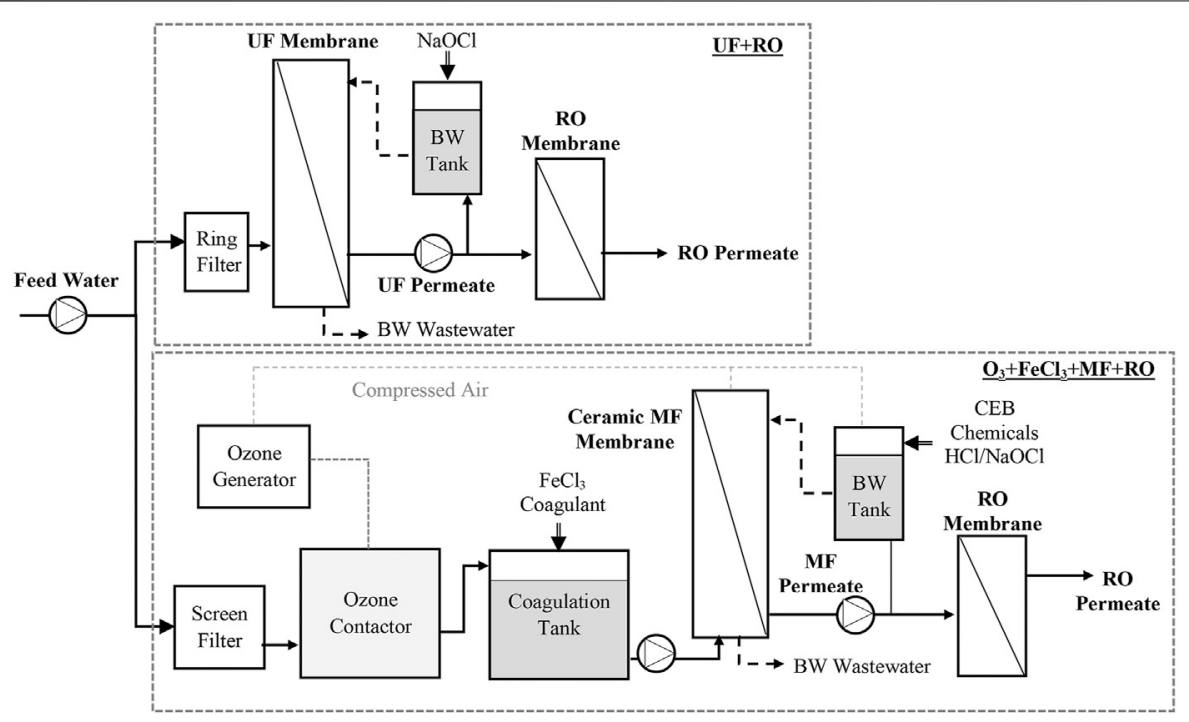

FIGURE 2 | Schematic of the two tertiary treatment systems, adapted from Lehman and Liu. (2009).

contact tank. The ozone generator was adjusted to reach ozone concentrations in feed water at the membrane entry of $0-25 \mathrm{mg} / \mathrm{L}$.

Coagulation was performed by continuously adding $\mathrm{FeCl}_{3}$ to a in a coagulation tank with an average retention time of $60 \mathrm{~s}$. Iron chloride was used as coagulant as it destabilizes micro-particles in water and promotes aggregation of NOM's which can easily be removed by high-pressure BW in the MF membrane (Yonekawa, Tomita, and Watanabe 2004). The MF unit consists of a monolithic ceramic membrane made in alumina, with insideout channels, a total surface area of $0.4 \mathrm{~m}^{2}$ and $0.1 \mu \mathrm{m}$ nominal pore size, operated in dead-end mode More detailed membrane characteristics are listed in Figure 1. The pilot plant can reach a treatment capacity (permeate production) of $160 \mathrm{~L} / \mathrm{h}$ and a feed/ permeate conversion of around $99 \%$. The MF membrane has two phases of operation, a filtration stage and backwash. At the completion of each filtration phase either a normal highpressure backwash lasting $20 \mathrm{~s}$ is applied, or a CEB lasting 15-30 min is applied. The chosen BW:CEB ratio can be varied according to the severity of membrane fouling. A full description of the membrane cleaning procedure of the MF membrane is described in Membrane Cleaning Protocols. The resulting effluent from the MF unit was used as feed for the RO unit which is equipped with two small scale commercial RO membrane units in series and is able to treat up to $30 \mathrm{~L} / \mathrm{h}$, with a recovery rate of over $75 \%$.

Both pilot plants were fully automatized, running without continuous supervision and recording data process such as water flows, pressure, transmembrane pressure (TMP), temperature, membrane permeability, Redox, $\mathrm{pH}$, as well as water quality parameters such as turbidity and conductivity.

\section{Feed Water Composition}

The WWTP of the brewery comprises a complete physicochemical and biological treatment including coagulation. The
TABLE 1 | Brewery secondary effluent wastewater physico-chemical and chemical characteristics.

\begin{tabular}{lc}
\hline Parameter & Feed water \\
\hline $\mathrm{pH}$ & $8.4 \pm 0.1$ \\
Conductivity $(\mu \mathrm{S} / \mathrm{cm})$ & $3,557.5 \pm 231.1$ \\
$\mathrm{COD}(\mathrm{mg} / \mathrm{L})$ & $49.2 \pm 30.6$ \\
$\mathrm{TSS}(\mathrm{mg} / \mathrm{L})$ & $4.5 \pm 4.2$ \\
Nitrate $(\mathrm{mg} / \mathrm{L})$ & $4.0 \pm 1.3$ \\
Turbidity (NTU) & $3.9 \pm 1.2$
\end{tabular}

physico-chemical treatment aims to remove TSS and total phosphorus, and includes the following processes: homogenization, $\mathrm{pH}$ regulation, chemical coagulation (with aluminium polychloride) and primary settling. The biological treatment is divided into four stages: high-rate anaerobic bioreactor, phosphorus and nitrogen removal, activated sludge reactor and secondary settling.

The resultant secondary treated effluent was used as feed stream for the two tertiary treatment pilot-plants evaluated in this study. The feed water characteristics were obtained from $24 \mathrm{~h}$ integrated samples and the results are summarized in Table 1. As can be seen, the brewery secondary effluent contains a high concentration of organic matter and nitrates, $49.2 \mathrm{mg} / \mathrm{L}$ and $4 \mathrm{mg} / \mathrm{L}$ respectively, higher than municipal secondary treatment effluent due to the presence of ethanol and other chemical additives in the brewing process.

\section{Towards Water Reuse Regulations}

All the analysis was performed as per standard methods of water and wastewater analysis (APHA-AWWA-WEF, 2005). $\mathrm{pH}$, turbidity, redox, conductivity, $\mathrm{COD}$, ammonia $\left(\mathrm{NH}_{4}{ }^{+}\right)$, nitrate $\left(\mathrm{NO}_{3}{ }^{-}\right)$and phosphate $\left(\mathrm{PO}_{4}{ }^{2-}\right)$ were analysed using instruments 
by $\mathrm{HACH}$, United States. Water samples were also analysed by an external laboratory for the microbiological parameters, heavy metals and complex organic compounds shown in Table 4, to evaluate the product water quality compared to the legal limits indicated by legislation; EU Directive 2020/741 European nonpotable wastewater reuse legislation; R.D.1620/2007 Spanish regenerated wastewater legislation; R.D. 140/2003 Spanish Drinking water standard legislation. The analytical methods used for each parameter are described in the specific legislation.

\section{Membrane Cleaning Protocols}

Membrane fouling in MF/UF and RO membranes was evaluated through the increase of transmembrane pressure (TMP). This parameter indicates the membrane fouling propensity when a specific water quality is treated under certain operation parameters (flux, filtration run length, cleaning procedures). TMP data was continuously monitored to determine the fouling kinetics and the extent of membrane fouling. Cleaning strategies were required to restore the membrane permeability. Mechanical backwash cleanings were performed after each filtration cycle.

Chemical cleanings can be divided into Chemically Enhanced Backwash (CEB) and Clean-In-Place (CIP) process. CEB protocol includes the addition of the chemical reagent into the backwash, with short contact time whereas the CIP protocol is more intense and includes reagent preparation, recirculation and soaking. CIPs are performed when the membrane is irreversibly fouled and when the permeability cannot be restored with CEBs. In this study, CIPs were employed when the TMP increased over 2 bar for the UF and MF membranes or at the start of a different Experimental stage.

In the UF pilot plant, a combination of mechanical and chemical membrane cleanings were employed based on backwash and assisted by air scouring to remove the foulants adhered to the pores and membrane surface. The cleaning intervals consisted of $60 \mathrm{~s}$ of $\mathrm{CEB}$ by dosing $1 \mathrm{ppm} \mathrm{NaOCl}$ and passing the chlorinated water at $6 \mathrm{~m}^{3} / \mathrm{h}$ through the membrane from the permeate side to the feed side, followed by $60 \mathrm{~s}$ backwash with only UF filtrate to remove any residual hypochlorite. The chemical cleanings start when the TMP reach a maximum programmed TMP, by elapsed time or at the end of each filtration stage.

On the other hand, the reagents tested in CIPs for the UF membrane were hypochlorite as oxidant reagent, citric acid and hydrochloric acid as acidic agents and an enzymatic cleaner $\left(\right.$ Tergazyme $\left.{ }^{\circledR}\right)$. These were used in concentrations ranging $1,000-2000 \mathrm{ppm}$ ( $\mathrm{NaOCl}), 450-750 \mathrm{ppm}$ (citric acid), $\mathrm{HCl}$ to reach a $\mathrm{pH}$ of 3 and $100 \mathrm{ppm}$ (Tergazyme). Cleaning, soaking and membrane washing times varied from 30 to $120 \mathrm{~min}$, $30-720 \mathrm{~min}$ and 30-120 min, respectively.

Ceramic MF membranes present high chemical and mechanical resistance and the cleaning protocols can be more intensive than polymeric UF membranes. Mechanical cleanings were based on high air-water pressure backwash at 5 bar followed by air flushing at $2 \mathrm{bar}$ and rinsing before another filtration cycle. High pressure loosens accumulated solids on the membrane surface which are blown away by the air flushing.
The chemical cleanings or CEBs also comprised of a highpressure backwash and air flushing but included sodium hypochlorite $(\mathrm{NaOCl})$ dosing at $13 \%$ and hydrochloric acid $(\mathrm{HCl})$ dosing at $33 \%$, on an alternating basis. These include a soaking step with the chemical added which typically lasts $15-30 \mathrm{~min}$. CEB chemical cleaning is not applied as frequently as normal backwash but can extend the filtration times. CIP procedures with the MF membrane included $\mathrm{NaOCl}$ up to $3000 \mathrm{ppm}$ and $\mathrm{HCl}$ at 5\% with overnight soaking. All these chemical products met the regulatory standards for food grade reagents and can be used in the context of drinking water treatment.

\section{RESULTS AND DISCUSSION}

In order to compare the treatment performance of the two tertiary treatment systems studied in this work, the following three criteria were evaluated: operational conditions, cleaning strategies and the quality of the resulting water. The results of these criteria are outlined and discussed in the following sections.

\section{Operation Conditions $\mathrm{UF}+\mathrm{RO}$}

In the UF + RO system, both technologies were operated individually with different operational parameters. The UF pilot plant was operated for 4 months at increasing fluxes and varying filtration times to identify the ideal operational conditions of the UF membranes in dead-end mode. In total, 10 stages were carried-out with fluxes ranging from 20 to $42 \mathrm{~L} /$ $\mathrm{m}^{2} \cdot \mathrm{h}$ (LMH) and filtration times ranging from 10 to $45 \mathrm{~min}$, as shown in Table 2. During the whole period of operation, a chemically enhanced backwash (CEB) was employed after each filtration cycle by dosing $100 \mathrm{ppm}$ of $\mathrm{NaOCl}$ for $60 \mathrm{~s}$ and washing the membrane with UF permeate for another $60 \mathrm{~s}$.

To determine the extent of membrane fouling, the reduction in permeability after each stage was calculated (Figure 3). At low fluxes of $20-25 \mathrm{LMH}$, the initial membrane permeability was relatively low, the membrane could be operated with longer filtration times of up to $45 \mathrm{~min}$ without any significant increase in TMP or loss in permeability. However, at increasing fluxes of over $25 \mathrm{LMH}$, the filtration times had to be reduced to below $30 \mathrm{~min}$ as the permeability decreased significantly due to severe fouling.

Furthermore, for every stepped increase in filtration time, the loss of permeability at similar fluxes increased accordingly. Only stages 7 and 8 showed an inconsistent loss in permeability, lower than expected, probably because membrane cleaning prior to filtration was not as effective and both stages began with a lower initial membrane permeability. In a study by Acero et al. (2010) on the treatment of secondary effluent with UF membranes, it was found that UF suffers from rapid flux decline due to the presence of soluble microbial products such as extracellular polymeric substances that form a biofilm on the membrane surface.

An interesting observation is that the fluxes and filtration times obtained with the UF membranes employed in this study were on 
TABLE 2 | Summary of operational parameters set during the 10 operation stages of UF.

\begin{tabular}{|c|c|c|c|c|c|c|}
\hline Stage & $\begin{array}{l}\text { Feed flow } \\
\left(\mathrm{m}^{3} / \mathrm{h}\right)\end{array}$ & $\begin{array}{l}\text { Filtration time } \\
\text { (min) }\end{array}$ & Flux (LMH) & $\begin{array}{l}\text { Initial permeability } \\
\text { (LMH.bar }{ }^{-1} \text { ) }\end{array}$ & $\begin{array}{l}\text { Final permeability } \\
\left(\mathrm{LMH} \cdot \mathrm{bar}^{-1}\right)\end{array}$ & $\begin{array}{c}\text { Loss in } \\
\text { permeability (\%) }\end{array}$ \\
\hline 1 & 2.1 & 45 & 20.1 & 27.9 & 22.5 & 19.4 \\
\hline 2 & 2.3 & 20 & 22.1 & 22.7 & 22.9 & -0.9 \\
\hline 3 & 2.4 & 30 & 23.0 & 26.6 & 24.3 & 8.6 \\
\hline 4 & 2.6 & 30 & 25.0 & 41.0 & 25.3 & 38.3 \\
\hline 5 & 2.6 & 45 & 25.0 & 37.0 & 18.9 & 48.9 \\
\hline 6 & 2.7 & 15 & 26.5 & 48.7 & 21.7 & 55.4 \\
\hline 7 & 2.7 & 20 & 26.5 & 42.1 & 21.8 & 48.2 \\
\hline 8 & 3.0 & 30 & 29.4 & 26.6 & 21.2 & 20.3 \\
\hline 9 & 4.1 & 30 & 40.2 & 112.4 & 31.0 & 72.4 \\
\hline 10 & 4.3 & 10 & 42.2 & 60.6 & 24.4 & 59.7 \\
\hline
\end{tabular}

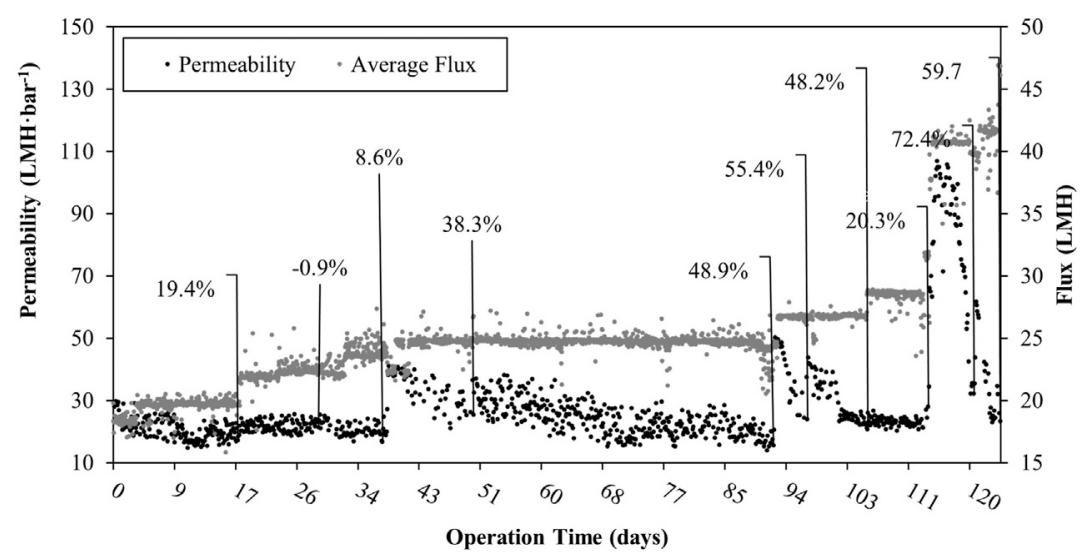

FIGURE 3 | Time-course of UF permeability and flux for the long-term operation with the corresponding loss in permeability after each stage.

the lower end of the typical PVDF membrane operating conditions used in wastewater treatment. Usually, the operating conditions are 17-68 LMH and 15-60 min backwash intervals. A possible explanation is that fouling was more severe than expected due to low MW organic foulants depositing on the inner surfaces of the fibres (Zhang et al., 2009), suggesting that a previous coagulation/ flocculation step would be required to enhance the performance of the UF unit (Simate et al., 2011). Finally, a flux range of 25-30 LMH with 15-20 min of filtration time were found to be the ideal operating conditions to obtain longer production periods and avoid frequent CIP membrane cleaning.

The RO unit was designed to treat a feed flow of $4.50 \mathrm{~m}^{3} / \mathrm{h}$ but the UF plant was limited to producing $3 \mathrm{~m}^{3} / \mathrm{h}$ of permeate, hence the RO unit was fed with UF permeate on a semicontinuous basis for a duration of 2 months. In addition, the flux had to be reduced to an average of $21 \mathrm{LMH}$, lower than the designed capacity of $30 \mathrm{LMH}$. The two spiral wound membrane modules were operated in series in two steps with recirculation of the concentrate. During the period of operation, the variation in TMP of the two modules was monitored at varying recovery rates $(50-90 \%)$ and concentrate rejection rates $(70-90 \%)$.

Higher recovery and rejection rates did not result in a significant increase in TMP, with constant TMP values averaging 0.25 and 0.08 bar for Step 1 and 2, respectively. Although these results demonstrate a low fouling propensity of the $\mathrm{RO}$ membranes, it is important to note that the RO unit was designed to treat higher fluxes. In general, RO combined with other physical separation techniques is a preferred conditioning method because of its simple automation, small space requirements and low use of chemicals for regeneration (Meshksar, Roostaee, and Rahimpour 2020).

\section{$\mathrm{O}_{3}+$ Coagulation $+\mathrm{MF}+\mathrm{RO}$}

Unlike the UF + RO system, the pilot plant with the advanced combination of ozone, coagulation and membrane filtration processes was operated with the MF and RO units combined in the same treatment train. The MF membrane with enhanced ozonation and coagulation was operated for a duration of 2 months. In total, 8 stages were tested by changing the following parameters systematically: ozone dosing (1-25 ppm), $\mathrm{FeCl}_{3}$ coagulant dosing (1-12 ppm), filtration times (8-30 min) and MF flux (80-125 LMH), as summarised in Table 3. After each filtration cycle the MF membrane was cleaned with a BW and a $\mathrm{CEB}$ by employing first $\mathrm{NaOCl}$ to remove organic matter and consequently $\mathrm{HCl}$ to remove any inorganic depositions. The ratio of $\mathrm{CEB}$ to $\mathrm{BW}$ was also changed throughout the stages of operation from $1: 2$ to $1: 10$. 
TABLE 3 | Summary of operational parameters set during the 8 operation stages of the ceramic MF membrane.

\begin{tabular}{|c|c|c|c|c|c|c|}
\hline Stage & $\begin{array}{l}\text { Filtration time } \\
\text { (min) }\end{array}$ & Flux (LMH) & $O_{3}(p p m)$ & $\mathrm{FeCl}_{3}(\mathrm{ppm})$ & CEB:BW & $\begin{array}{c}\text { Average TMP } \\
\text { (bar) }\end{array}$ \\
\hline 1 & 8 & 84.0 & 1 & 1 & $1: 2$ & 0.84 \\
\hline 2 & 15 & 112.3 & 1 & 2 & $1: 4$ & 0.54 \\
\hline 3 & 30 & 116.6 & 1 & 2 & $1: 8$ & 0.60 \\
\hline 4 & 30 & 125.5 & 1 & 3 & $1: 8$ & 0.41 \\
\hline 5 & 30 & 121.6 & 25 & 3 & $1: 8$ & 0.39 \\
\hline 6 & 30 & 110.9 & 25 & 2 & $1: 8$ & 0.55 \\
\hline 7 & 30 & 111.3 & 0 & 6 & $1: 10$ & 0.79 \\
\hline 8 & 30 & 108.6 & 0 & 12 & $1: 10$ & 1.08 \\
\hline
\end{tabular}

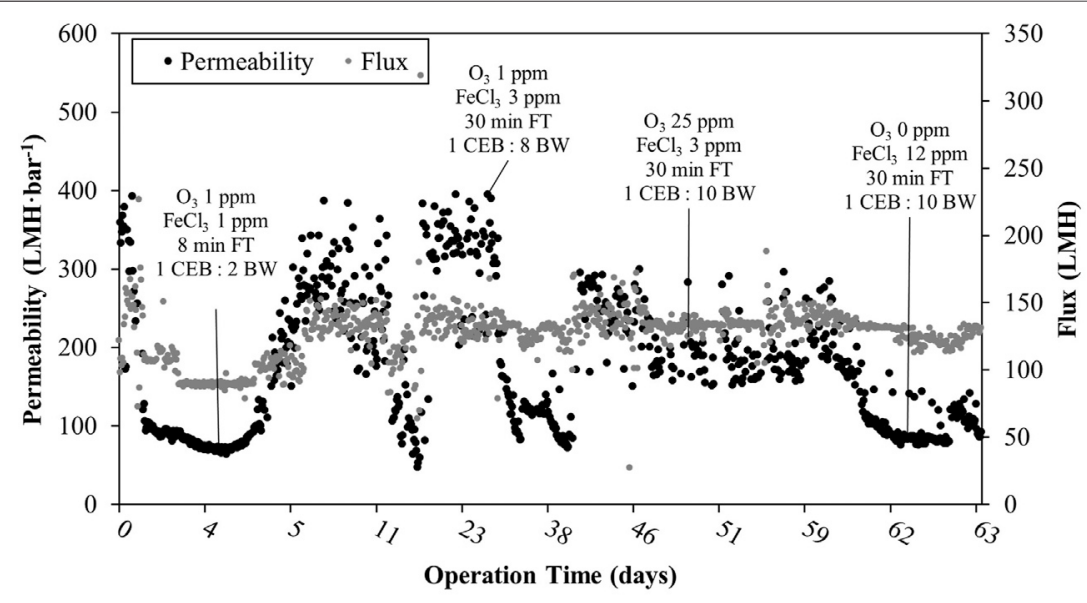

FIGURE 4 | Time-course of permeability and flux plotted for the long-term operation of the MF ceramic membrane, showing the operation conditions for 4 key stages.

In order to determine the ideal operating conditions for the MF membrane, the TMP and resulting permeability of the ceramic membrane were constantly monitored. At the designed ozone dosing levels of $1 \mathrm{ppm}$ of dissolved $\mathrm{O}_{3}$ at membrane entry and the designed coagulant dosing levels of $1 \mathrm{ppm}$ of $\mathrm{FeCl}_{3}$, the filtration times had to be reduced to as low as 8 min with a CEB:BW ratio of 1 : 2 to avoid rapid fouling and the TMP reaching 2 bar. However, low filtration times at an average flux of $80 \mathrm{LMH}$ meant that the RO unit could not be operated continuously with MF permeate. On the other hand, at greater coagulant dosing levels of 3-6 ppm, the filtration times could be increased to $30 \mathrm{~min}$, with a greater CEB:BW ratio of 1 : 8 and the MF could be coupled with RO.

The maximum permeability obtained with these conditions was $400 \mathrm{LMHbar}^{-1}$, as shown in Figure 4. A study using a similar ceramic membrane, with a larger surface area of $25 \mathrm{~m}^{2}$ and for the treatment of secondary wastewater reported ideal operating fluxes of $170 \mathrm{LMH}$, corresponding to permeability values ranging from 400 to $600 \mathrm{LMHbar}^{-1}$ (Lehman and Liu 2009). In this earlier study, the CEB frequency used was once every 2 days, a much lower CEB application than the current study which employed a CEB every $4 \mathrm{~h}$. This can be attributed to a much higher concentration of TSS and COD in the brewery wastewater used in this study.
Excessive coagulation was found to reduce drastically the membrane treatment capacity as coagulant dosing concentration of $>10 \mathrm{ppm}$ led to a decrease in permeability by $100 \mathrm{LMHbar}^{-1}$. An explanation for the improved performance at higher coagulant concentrations of 3-6 ppm is that the brewery wastewater is rich in soluble organics, such as polyphenols, that complex with the $\mathrm{FeCl}_{3}$ and inhibit the coagulation of suspended solids (Götz et al., 2014). Thus, higher concentrations of $\mathrm{FeCl}_{3}$ are needed for an optimal coagulation.

Increasing the ozone concentration to $25 \mathrm{ppm}$ was found to have no significant impact on the extent of membrane fouling. Ozone is expected to decompose and degrade colloidal NOMs, which form organic gels adhered onto membrane surfaces, thus reducing membrane fouling (Oh et al., 2007; Lehman and Liu 2009). However, Schlichter, Mavrov, and Chmiel (2003) also reported no influence of ozone on filtration behaviour. Since pre-ozonation has been reported to break down colloidal materials, especially those in the MW range of $1.8-67 \mathrm{kDa}$, it is possible that the feed water used in this study contained lower MW organics that are not degraded by ozone but require higher $\mathrm{FeCl}_{3}$ pre-coagulation doses.

In almost every stage, the obstruction of membrane channels with solid particles caused spikes in TMP that 
TABLE 4 | Summary of results from the water quality analyses of the main streams resulted from the main processes of both treatment plants.

\begin{tabular}{|c|c|c|c|c|c|c|c|c|c|c|}
\hline \multirow[t]{2}{*}{ Parameters } & \multicolumn{3}{|c|}{ UF-RO } & \multicolumn{4}{|c|}{$\mathrm{O}_{3}$-MF-RO } & \multirow{2}{*}{$\begin{array}{l}\text { EU 2020/ } \\
741^{a}\end{array}$} & \multirow{2}{*}{$\begin{array}{l}\text { RD 1620/ } \\
2007^{b}\end{array}$} & \multirow{2}{*}{$\begin{array}{l}\text { RD 140/ } \\
2003^{c}\end{array}$} \\
\hline & UF feed & $\begin{array}{c}\text { UF } \\
\text { permeate }\end{array}$ & $\begin{array}{c}\text { RO } \\
\text { permeate }\end{array}$ & Raw feed & MF feed & $\begin{array}{c}\text { MF } \\
\text { permeate }\end{array}$ & $\begin{array}{c}\text { RO } \\
\text { permeate }\end{array}$ & & & \\
\hline $\mathrm{pH}$ & $8.38 \pm 0.10$ & $8.39 \pm 0.13$ & $7.05 \pm 0.42$ & $8.40 \pm 1.75$ & $8.35 \pm 1.75$ & $8.29 \pm 1.72$ & $6.84 \pm 1.85$ & - & - & $6.5-9.5$ \\
\hline Redox (mV) & - & - & - & $175 \pm 98.0$ & $173 \pm 97.1$ & $176 \pm 99.7$ & $226 \pm 88.2$ & - & - & - \\
\hline Conductivity ( $\mu \mathrm{S} / \mathrm{cm})$ & $3,560 \pm 231$ & $3,240 \pm 381$ & $120 \pm 65.0$ & $\begin{array}{c}3,690 \pm \\
1,470\end{array}$ & $3,550 \pm 436$ & $3,550 \pm 433$ & $361 \pm 339$ & - & - & 2,500 \\
\hline Turbidity (NTU) & $3.90 \pm 1.21$ & $1.35 \pm 2.56$ & $0.22 \pm 0.06$ & $9.52 \pm 9.87$ & $8.81 \pm 5.31$ & $1.16 \pm 2.16$ & $0.20 \pm 0.06$ & $\leq 5$ & $\leq 10$ & 1 \\
\hline $\mathrm{NH}_{4}^{+}(\mathrm{mg} / \mathrm{L})$ & $<2.00$ & $<2.00$ & $<2.00$ & $<2.00$ & $<2.00$ & $<2.00$ & $<2.00$ & - & - & - \\
\hline $\mathrm{NO}_{3}^{-}(\mathrm{mg} / \mathrm{L})$ & $4.01 \pm 1.26$ & $2.94 \pm 0.95$ & $0.77 \pm 0.29$ & $3.42 \pm 2.00$ & $3.45 \pm 2.07$ & $3.57 \pm 2.02$ & $1.82 \pm 1.23$ & - & - & 50 \\
\hline $\mathrm{PO}_{4}{ }^{2-}(\mathrm{mg} / \mathrm{L})$ & $<0.50$ & $<0.50$ & $<0.50$ & $<0.50$ & $<0.50$ & $<0.50$ & $<0.50$ & - & - & - \\
\hline COD (mg/L) & $49.2 \pm 30.7$ & $23.6 \pm 12.5$ & $3.86 \pm 6.62$ & $111 \pm 22.8$ & $78.2 \pm 14.0$ & $79.2 \pm 22.8$ & $4.29 \pm 12.0$ & - & - & - \\
\hline TSS (mg/L) & $4.45 \pm 4.18$ & $0.22 \pm 0.06$ & $0.00 \pm 0.00$ & $19.5 \pm 16.8$ & $17.6 \pm 17.3$ & $0.00 \pm 0.00$ & $0.00 \pm 0.00$ & $\leq 10$ & $\leq 20$ & - \\
\hline $\begin{array}{l}\text { Colony number } 22^{\circ} \mathrm{C}(\mathrm{CFU} / \\
100 \mathrm{ml})\end{array}$ & - & $492 \pm 651$ & $125 \pm 65.8$ & - & - & $\begin{array}{c}6,700 \pm \\
6,080\end{array}$ & $\begin{array}{c}3,650 \pm \\
2,330\end{array}$ & - & - & - \\
\hline $\begin{array}{l}\text { Escherichia Coli } 37^{\circ} \mathrm{C} \\
(\mathrm{CFU} / 100 \mathrm{ml})\end{array}$ & - & $49.8 \pm 64.7$ & $0.00 \pm 0.00$ & - & - & $68.2 \pm 79.0$ & $0.00 \pm 0.00$ & $\leq 10$ & - & 0 \\
\hline Intestinal worms (eggs/10L) & - & n.d & n.d & - & - & n.d & n.d & $\leq 1$ & $\leq 1$ & - \\
\hline Legionella (CFU/100 ml) & - & n.d & n.d & - & - & n.d & n.d & $<1,000$ & $\leq 100$ & - \\
\hline $\begin{array}{l}\text { Enterococcus (CFU/ } \\
100 \mathrm{ml} \text { ) }\end{array}$ & - & 0 & 0 & - & - & 0 & 0 & - & 0 & 0 \\
\hline Clostridium (CFU/100 ml) & - & 0 & 0 & - & - & 0 & 0 & - & - & 0 \\
\hline Chloride ( $\mu \mathrm{g} / \mathrm{L})$ & - & $<0.1$ & $<0.1$ & - & - & $<0.05$ & $<0.05$ & - & - & 1 \\
\hline Fluoride ( $\mu \mathrm{g} / \mathrm{L})$ & - & 0.36 & 0.05 & - & - & $<0.075$ & $<0.015$ & - & - & 1.5 \\
\hline Boron ( $\mu \mathrm{g} / \mathrm{L})$ & - & 0.019 & 0.026 & - & - & $0.04 \pm 0.01$ & $0.05 \pm 0.01$ & - & - & 1 \\
\hline Benzene ( $\mu \mathrm{g} / \mathrm{L})$ & - & $<0.010$ & $<0.010$ & - & - & $<1.0$ & $<0.30$ & - & - & 1 \\
\hline Cyanide ( $\mu \mathrm{g} / \mathrm{L})$ & - & $<12$ & $<12$ & - & - & $<12$ & $<12$ & - & - & 50 \\
\hline Di-chloroethane ( $\mu \mathrm{g} / \mathrm{L})$ & - & $<1.0$ & $<1.0$ & - & - & $<1$ & $<0.30$ & - & - & 3 \\
\hline Total trihalomethanes $(\mu \mathrm{g} / \mathrm{L})$ & - & 29 & 2.8 & - & - & $<4$ & $<4$ & - & - & 100 \\
\hline Microcystine (楍/L) & - & $<0.7$ & $<0.7$ & - & - & $<0.20$ & $<0.20$ & - & - & 1 \\
\hline Trichloroethene ( $\mu \mathrm{g} / \mathrm{L})$ & - & $<1.0$ & $<1.0$ & - & - & $<0.1$ & $<0.5$ & - & - & 10 \\
\hline Benzo(b)fluorantene ( $\mu \mathrm{g} / \mathrm{L})$ & - & $<0.05$ & $<0.05$ & - & - & $<0.05$ & $<3$ & - & - & - \\
\hline Antimony ( $\mu \mathrm{g} / \mathrm{L})$ & - & $<1.0$ & $<1.0$ & - & - & $1.7 \pm 1.20$ & $<1.0$ & - & - & 5 \\
\hline Iron ( $\mu \mathrm{g} / \mathrm{L})$ & - & $65.3 \pm 47.6$ & $8.21 \pm 5.11$ & - & - & $69.5 \pm 4.24$ & $<5$ & - & - & 200 \\
\hline Aluminium ( $\mu \mathrm{g} / \mathrm{L})$ & - & $829 \pm 611$ & - & - & - & $227 \pm 284$ & $<10$ & - & - & - \\
\hline Copper ( $\mu g / L)$ & - & 0.009 & $<0.001$ & - & - & & $<0.010$ & - & - & 2 \\
\hline Cadmium ( $\mu \mathrm{g} / \mathrm{L})$ & - & 0.03 & $<0.024$ & - & - & $<0.024$ & $<1.0$ & - & - & 5 \\
\hline Chromium ( $\mu \mathrm{g} / \mathrm{L})$ & - & $<5.0$ & $<5.0$ & - & - & $19.0 \pm 13.4$ & $<5.0$ & - & - & 50 \\
\hline Nickel ( $\mu \mathrm{g} / \mathrm{L})$ & - & 2 & $<1.2$ & - & - & $9.85 \pm 11.5$ & $<1.0$ & - & - & 20 \\
\hline Lead $(\mu \mathrm{g} / \mathrm{L})$ & - & $<0.36$ & $<0.36$ & - & - & $<0.36$ & $<1.0$ & - & - & 10 \\
\hline Selenium ( $\mu \mathrm{g} / \mathrm{L})$ & - & $<0.3$ & $<0.3$ & - & - & $<0.3$ & $<1.0$ & - & - & 10 \\
\hline Mercury $(\mu g / L)$ & - & $<0.015$ & $<0.015$ & - & - & $<0.015$ & $<0.10$ & - & - & 1 \\
\hline Total plaguicides ( $\mu \mathrm{g} / \mathrm{L})$ & - & $<0.05$ & $<0.05$ & - & - & - & - & - & - & - \\
\hline
\end{tabular}

${ }^{a}$ European non-potable wastewater reuse legislation water quality limits.

${ }^{b}$ Spanish regenerated wastewater for use in industrial services water quality limits.

${ }^{c}$ Spanish potable reuse legislation water quality limits.

could not be reversed with a higher CEB:BW ratio and required an intensive CIP procedure. These membrane pore obstructions were the main challenge in operating the ceramic MF membrane. Despite of this, the ideal operating conditions were found to be a flux of $125 \mathrm{LMH}$, a coagulant dosing concentration of $3 \mathrm{ppm}$ and a CEB:BW ratio of 1:8. When compared to the ideal operating conditions of the UF system, the ceramic MF membrane achieves almost 5 times higher flux with a similar extent of fouling. However, when considering the chemical consumption, the ceramic membrane requires three chemicals instead of one $\left(\mathrm{FeCl}_{3}\right.$, $\mathrm{NaOCl}, \mathrm{HCl}$ ), and at higher concentrations. Park et al. (2015) performed a life cycle cost analysis on ceramic and polymeric membranes used in a WWTP and concluded that the greater capital costs of installing ceramic membranes were outweighed by the operation costs. Although ceramic membranes have a greater chemical demand, replacing polymeric membranes when irreversibly fouled raises the operation costs considerably.

The RO unit was designed to treat a feed flow of $28 \mathrm{~L} / \mathrm{h}$, equivalent to a flux of $11 \mathrm{LMH}$, and a recovery of $75 \%$. However, due to the fouling challenges of the MF membrane and the consequent lack of MF permeate as feed stream, the RO unit was operated at lower fluxes, progressively increasing from 1.8-4.3 LMH. This resulted in a stable and low TMP that averaged only 0.34 bar.

\section{Clean-In-Place Cleaning}

Severe fouling of the UF and MF membranes required Clean-InPlace (CIP) procedures to restore the permeability of the membrane and proceed to the next stages of operation. Several CIPs were tested on both the UF and MF membranes 
and are resumed in the Supplementary Material in Supplementary Figure S1. For the UF membrane, CIPs were performed when the permeability dropped below $25 \mathrm{LMHbar}^{-1}$, which generally occurred every 2 weeks. Typical membrane cleaning intervals are between 1 and 6 months, indicating the severe irreversible fouling depositing on the UF membranes (Crittenden et al., 2005).

Sodium hypochlorite was found to be the most effective cleaning agent with concentrations of $1500 \mathrm{ppm}$, just below the maximum chlorine concentration limit of $2000 \mathrm{ppm}$ recommended by the membrane supplier, effectively restoring permeability between $50-120 \%$. On the other hand, the combination of $\mathrm{NaOCl}$ to eliminate organic matter and biofilm, citric acid at $\mathrm{pH} 3$ for the removal of inorganic depositions and Tergazyme was most effective in tackling fouling, albeit its higher chemical cost demand.

An explanation for the extent of irreversible fouling could be a high concentration of low MW NOM fraction in the feed wastewater blocking the membrane pores and reducing the efficiency of CIPs. It has been reported that the use of $\mathrm{NaOH}$ at $2 \%$ before the application of citric acid, can be very efficient at removing low MW organic foulants (Zhang et al., 2009). In a study that employed UF membranes with a silex filter pretreatment to treat power industry wastewater, the use of continuous inline chlorination lowered the CIP frequency to every 4-6 months (Suárezet al., 2013).

In contrast, the greater chemical resistance of the MF membrane allowed for higher concentrations of cleaning agents. CIP procedures were generally employed after severe obstruction of the ceramic membrane with solid particles, which occurred often. The most effective CIP was found to be the combination of $\mathrm{NaOCl}$ at concentrations of 2000-3,000 ppm and an overnight soaking with $5 \% \mathrm{HCl}$. Similar concentrations of hypochlorite plus overnight soaking were used to fully restore the permeability and efficiently increase the flux to $255 \mathrm{LMH}$, as reported by Lehman and Liu. (2009).

The drawback of using stronger cleaning solutions is the need for thorough washing with water and the cost of using higher chemical concentrations. With a similar ceramic membrane, (Dow and Duke, 2013), suggested a minimum of 90 days between CIPs, or when a filtration cycle reaches 1.5 bar, to restore membrane performance when using coagulant and ozone. Although the ceramic MF membrane has a greater chemical cleaning demand, the membrane performance can be recovered regularly, unlike the UF polymeric membranes that have shorter membrane lifetimes.

Since the frequency of CIP routines has a large bearing on the plant's operating costs, solving the problems of feed waters rich in organics and TMP spikes by implementing more effective pre-treatments could increase the competitiveness of both UF and MF treatment systems in brewery wastewater treatment.

\section{Water Quality}

One of the main objectives of this study is the comparison of the quality of water resulting from the two treatment systems. The results of water quality analyses from the main streams (feed and product of each process) are summarised in Table 4. Monitoring parameters have been selected to evaluate if the water quality fulfils the standards established by the European and Spanish regulation for water reuse. For this purpose, different final uses such use in industrial services (RD 1620/2007), irrigation (Directive 741/2020) and drinking water (RD 140/2003) have been considered.

\section{$\mathrm{UF}+\mathrm{RO}$}

The brewery wastewater used as feed for the UF unit showed significant fluctuations in organic matter (19-70 mg/L COD) and nitrate $(2.8-6.8 \mathrm{mg} / \mathrm{L})$ which were caused by irregular discharge peaks from the brewing process. Throughout the period of operation, the UF membrane was very effective in reducing suspended solids (99\%) and turbidity (87\%) due to the sifting effect of the $0.03 \mu \mathrm{m}$ membrane pore size. This reduction in turbidity, independent of feed turbidity, is one of the biggest advantages of UF over conventional pre-treatment systems (Zhang et al., 2009).

In contrast, a poorer and inconsistent elimination of organic matter (28\%), dissolved salts (9\%) and nitrates (4\%) was observed (Figure 5), in part due to these irregular discharge periods but also due to the low separation properties of dissolved compounds by UF membranes. Similar results for COD removal rates were obtained by Götz et al. (2014) using UF membranes to filter biologically treated brewery wastewater. On the other hand, a full-scale UF module with a capacity to treat $30 \mathrm{~m}^{3} / \mathrm{h}$ of brewery wastewater was reported to eliminate COD between 54 and 66\% (Chaitanyakumar et al., 2011). The limited reduction of nitrates by UF was also reported by Acero et al. (2010).

Although the UF permeate quality meets the requirements for agriculture irrigation (EU Directive 741/2020) in terms of suspended solids, it was found to exceed the $10 \mathrm{CFU} / 100 \mathrm{ml}$ limit for E. Coli. The presence of this faecal contamination indicator in the UF permeate is not related to influent quality or defective membranes, but as reported in previous studies, is mainly due to contamination of the membrane in the permeate zone (Gómez et al., 2007). UF permeate is an excellent stream to be used in industrial services described in the RD 1620/2007: irrigation of recreational areas, fire extinguisher systems, hosing down, and industrial vehicles washing.

After treatment with the RO unit, the final water produced was of excellent quality, meeting all the limits for drinking water (RD 140/2003). The RO membranes showed a constantly high rejection of salts $(95 \%)$ and lower but still efficient elimination of organic matter (75\%) and nitrate (74\%), as shown in Figure 5. On the other hand, the lower removal of turbidity is attributed to the high elimination of suspended solids by UF. Similar rejections of organic matter were observed in an earlier study using NF membranes to treat effluent from biologically treated brewery wastewater, resulting in permeate COD concentrations below $5 \mathrm{mg} / \mathrm{L}$ (Van der Bruggen and Braeken 2006). In addition, two full-scale RO modules in series with a capacity to filter $30 \mathrm{~m}^{3} / \mathrm{h}$ of UF treated wastewater, were reported to reduce COD by $70-90 \%$ 


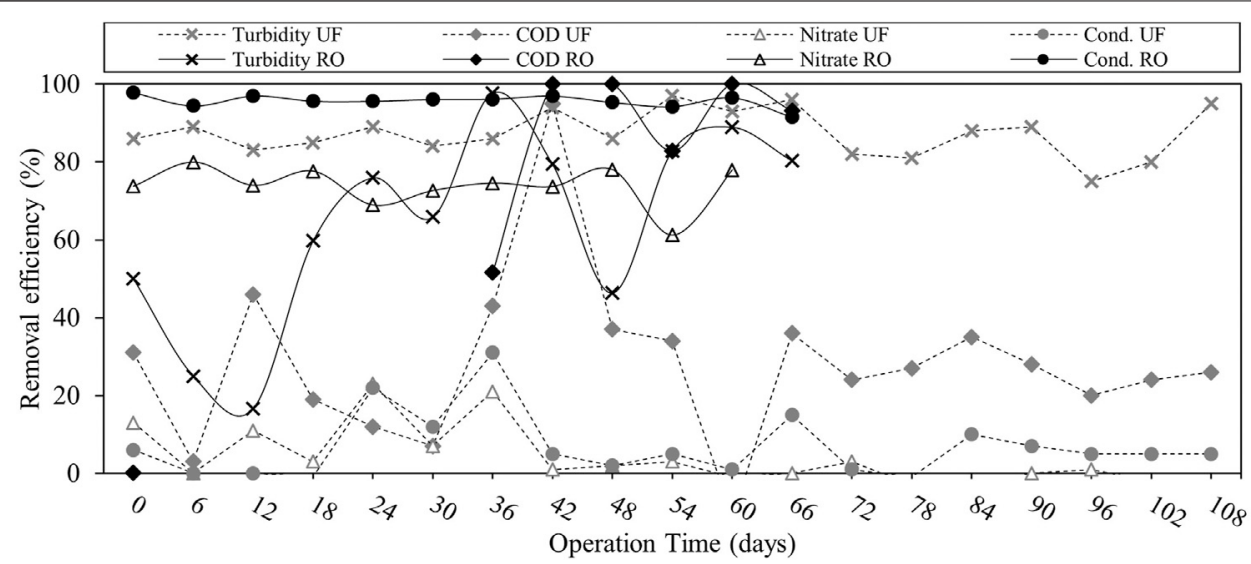

FIGURE 5 | Time-course of removal efficiency for turbidity, organic matter, nitrate and conductivity obtained by the UF and RO membranes in the UF + RO coupled treatment system.

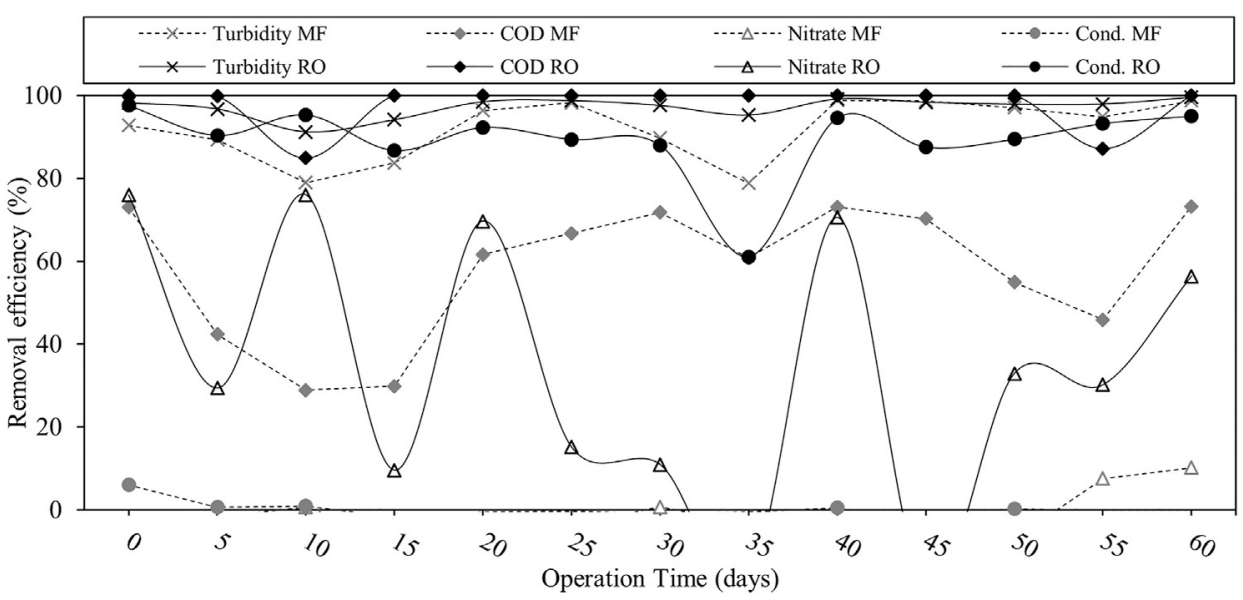

FIGURE 6 | Time-course of removal efficiency for turbidity, organic matter, nitrate and conductivity obtained by the MF and RO membranes in the ozonecoagulation-MF-RO treatment system.

and total dissolved solids up to $94 \%$ (Chaitanyakumar et al., 2011).

\section{$\mathrm{O}_{3}+$ Coagulation $+\mathrm{MF}+\mathrm{RO}$}

Even though the combined ozone, coagulation, MF and RO system employed a pre-treatment with a screen filter, the wastewater entering the MF membrane had a very high solids content (averaging $17.6 \mathrm{mg} / \mathrm{L}$ compared to the UF feed concentration of $4.5 \mathrm{mg} / \mathrm{L})$. The concentration of organic matter was also higher in the MF feed, whilst the nitrate and conductivity content was similar. Despite this difference in feed water quality, the elimination of suspended solids by the MF unit averaged $98 \%$, and COD removal was superior to the UF membrane with an average elimination of $34 \%$ (Figure 6). The eliminated COD is most likely attributed to particulate organic matter. An explanation for the greater elimination of solids and organic matter compared to UF could be the coagulation of suspended solids by the addition of $\mathrm{FeCl}_{3}$ and the oxidation of organic compounds by ozone.
In a recent study that coupled $\mathrm{MF}$ to $\mathrm{RO}$ in treating tannery wastewater, the MF membrane was reported to achieve 91\% COD reduction without a previous coagulation step (Bhattacharya et al., 2013). However, another study using a similar ceramic membrane reported very low COD reductions, with preozonation only affecting effluent colour (Dow and Duke, 2013). Besides COD and turbidity, the MF system showed a very poor elimination of dissolved nitrate and salts, lower than the UF membrane.

In contrast, the last RO treatment step showed a very high rejection of salts (90\%), organic matter (94\%) but a poor rejection of nitrates (38\%), as shown in Figure 6. It is interesting to note that the rejection of nitrate is irregular, and this fluctuation probably arises from the discharge of nitrogen-rich waste streams to the brewery WWTP. Likewise to the UF system, the MF permeate quality meets the requirements for agriculture irrigation (EU Directive 741/2020) in terms of suspended solids, however, it does not comply with the $10 \mathrm{CFU} / 100 \mathrm{ml}$ limit for E. Coli. 
This contrasts with the pathogen removal capacity observed by (Dow and Duke, 2013), whereby the presence of E. Coli was not found in the MF membrane product permeate. The authors attributed this to the enhanced backwash pathogen disinfection unique to this process. According to the RD 1620/ 2007, the MF permeate stream can also be used in industrial services. After treatment with the RO unit, the final water produced met all the limits for potable water reuse (RD 140/2003).

\section{CONCLUSION}

The main focus of this study was to compare the performance of two different membrane processes, $\mathrm{UF}+\mathrm{RO}$ and $\mathrm{O} 3+$ Coagulation $+\mathrm{MF}+\mathrm{RO}$, to treat secondary wastewater from the brewery industry. Long-term operation of both systems provided the following conclusions. Polymeric UF membrane filtration was found to suffer from severe membrane fouling which can be mitigated by increasing filtration intervals, limiting the production flux to 25-30 LMH, applying more frequent CIPs and if possible, implementing a coagulation pre-conditioning step.

On the other hand, the ceramic MF system could be operated at higher fluxes (125 LMH) with sufficient coagulant dosing (3-6 ppm) and more frequent chemical backwashes. It was found that ozone had no significant impact on coagulation and ceramic membrane fouling propensity. Although the MF membrane can achieve higher production rates than the polymeric UF membrane, the use of chemicals for coagulation, CEB and CIPs was greater.

A full life cycle cost analysis allows to weigh the capital costs, such as membrane installation, against the operating costs of both systems which include membrane replacement, chemicals and electricity consumption. Both UF and ceramic MF units produced treated water at a quality within the national regulatory framework for reuse in industrial services (RD 1620/2007). However, whilst the MF membrane showed a higher elimination of suspended solids and organic matter, the UF membrane exceeded in terms of nitrate and dissolved salts removal. The RO units, aside from their operational simplicity and reliability, showed a very high capacity to polish the UF and MF effluent streams to water quality standards apt for potable reuse.

\section{REFERENCES}

Acero, J. L., Benitez, F. J., Leal, A. I., Real, F. J., and Teva, F. (2010). Membrane Filtration Technologies Applied to Municipal Secondary Effluents for Potential Reuse. J. Hazard. Mater. 177 (1-3), 390-398. doi:10.1016/j.jhazmat.2009.12.045

Angelakis, A. N., and Durham, B. (2008). Water Recycling and Reuse in EUREAU Countries: Trends and Challenges. Desalination 218 (1-3), 3-12. doi:10.1016/ j.desal.2006.07.015

Ansari, A. J., Hai, F. I., Price, W. E., Drewes, J. E., and Nghiem, L. D. (2017). Forward Osmosis as a Platform for Resource Recovery from Municipal

\section{DATA AVAILABILITY STATEMENT}

The raw data supporting the conclusions of this article will be made available by the authors, without undue reservation.

\section{AUTHOR CONTRIBUTIONS}

MST carried out the experimental work and wrote the manuscript with technical support from JA and VM. PFL and YA supported with initial start-up and administrative tasks. VM and JFC supervised the project. FR, AR, JFC and VM conceived the original idea.

\section{FUNDING}

This project has received funding from the European Union's Horizon 2020 research and innovation program under grant agreement No 869318 for the project ULTIMATE (Industry Water-Utility symbiosis for a Smarter Water Society). Preliminary research was supported by the European Commission through the project ANSWER (Advanced Nutrient Solutions with Electrochemical Recovery, LIFE program, LIFE15 ENV/ES/00059). Rood Wit Blauw Water Systems was supported by a grant from the Dutch Government under the Partners for Water Programme (PVW4S17024).

\section{ACKNOWLEDGMENTS}

We gratefully thank the Mahou-San Miguel WWTP operators for their assistance on-site, the RWB staff for their constant support in operating the pilot plant, the IPROMA laboratory analysts for the water analyses, and the membrane providers DOW and METAWATER.

\section{SUPPLEMENTARY MATERIAL}

The Supplementary Material for this article can be found online at: https://www.frontiersin.org/articles/10.3389/fceng.2021.734233/ full\#supplementary-material

Wastewater - A Critical Assessment of the Literature. J. Membr. Sci. 529 (May), 195-206. doi:10.1016/j.memsci.2017.01.054

Anwar, N., and Rahaman, M. S. (2020). Membrane Desalination Processes for Water Recovery from Pre-treated Brewery Wastewater: Performance and Fouling. Separation Purif. Technology 252 (July), 117420. doi:10.1016/j.seppur.2020.117420 Attarde, D., Jain, M., Singh, P. K., and Gupta, S. K. (2017). Energy-Efficient Seawater Desalination and Wastewater Treatment Using Osmotically Driven Membrane Processes. Desalination 413 (July), 86-100. doi:10.1016/ j.desal.2017.03.010

Bhattacharya, P., Roy, A., Sarkar, S., Ghosh, S., Majumdar, S., Chakraborty, S., et al. (2013). Combination Technology of Ceramic Microfiltration and Reverse 
Osmosis for Tannery Wastewater Recovery. Water Resour. Industry 3, 48-62. doi:10.1016/j.wri.2013.09.002

Blandin, G., Verliefde, A., Comas, J., Rodriguez-Roda, I., and Le-Clech, P. (2016). Efficiently Combining Water Reuse and Desalination through Forward Osmosis-Reverse Osmosis (FO-RO) Hybrids: A Critical Review. Membranes 6 (3), 37. doi:10.3390/membranes6030037

Braeken, L., Van Der Bruggen, B., and Vandecasteele, C. (2004). Regeneration of Brewery Waste Water Using Nanofiltration. Water Res. 38 (13), 3075-3082. doi:10.1016/j.watres.2004.03.028

Cath, T. Y., Hancock, N. T., Lundin, C. D., Hoppe-Jones, C., and Drewes, J. E. (2010). A Multi-Barrier Osmotic Dilution Process for Simultaneous Desalination and Purification of Impaired Water. J. Membr. Sci. 362 (1-2), 417-426. doi:10.1016/j.memsci.2010.06.056

Chaitanyakumar, D., Unnisa, S. A., Rao, B., and Vasanth Kumar, G. (2011). "Efficiency Assessment of Combined Treatment Technologies: A Case Study of Charminar Brewery Wastewater Treatment Plant. Indian J. Fundam. Appl. Sci. 1 (2), 138-145.

Crittenden, J. C., Trussel, R. R., Hand, D. W., Howe, K. J., and Tchobanoglous, G. (2005). Water Treatment: Principles and Design. 2nd ed. Hoboken, NJ: John Wiley \& Sons.

Dow, N, D., and Duke, M. (2013). "Outcomes of the Australian Ozone/Ceramic Membrane Trial on Secondary Effluent." Water. J. Aust. Water Assoc. 40 (6), $45-51$.

Gómez, M., Plaza, F., Garralón, G., Pérez, J., and Gómez, M. A. (2007). A Comparative Study of Tertiary Wastewater Treatment by Physico-ChemicalUV Process and Macrofiltration-Ultrafiltration Technologies. Desalination 202 (1-3), 369-376. doi:10.1016/j.desal.2005.12.076

Götz, G., Geißen, S.-U., Ahrens, A., and Reimann, S. (2014). Adjustment of the Wastewater Matrix for Optimization of Membrane Systems Applied for Water Reuse in Breweries. J. Membr. Sci. 465, 68-77. doi:10.1016/j.memsci.2014.04.014

Hochstrat, R., Wintgens, T., Kazner, C., Melin, T., and Gebel, J. (2010). Options for Water Scarcity and Drought Management-The Role of Desalination. Desalination Water Treat. 18 (1-3), 96-102. doi:10.5004/dwt.2010.1347

Lehman, S. G., and Liu., L. (2009). Application of Ceramic Membranes with Preozonation for Treatment of Secondary Wastewater Effluent. Water Res. 43 (7), 2020-2028. doi:10.1016/j.watres.2009.02.003

Madaeni, S. S., and Mansourpanah, Y. (2006). Screening Membranes for COD Removal from Dilute Wastewater. Desalination 197 (1-3), 23-32. doi:10.1016/ j.desal.2006.01.015

Meshksar, M., Roostaee, T., and Rahimpour, M. R. (2020). "Membrane Technology for Brewery Wastewater Treatment," in Current Trends and Future Developments on (Bio-) Membranes: Membrane Technology for Water and Wastewater Treatment - Advances and Emerging Processes (Elsevier), 289-303. doi:10.1016/B978-0-12-816823-3.00010-1

Meyn, T., and Leiknes, T. (2010). Comparison of Optional Process Configurations and Operating Conditions for Ceramic Membrane MF Coupled with Coagulation/ Flocculation Pre-treatment for the Removal of NOM in Drinking Water Production. J. Water Supply: Res. Technology - AQUA 59 (2-3), 81-91. doi:10.2166/aqua.2010.044

Oh, B. S., Jang, H. Y., Hwang, T. M., and Kang, J.-W. (2007). Role of Ozone for Reducing Fouling Due to Pharmaceuticals in MF (Microfiltration) Process. J. Membr. Sci. 289 (1-2), 178-186. doi:10.1016/j.memsci.2006.11.052

Pankratz, T. (2004). Desalination Technology Trends. Biennial Rep. Seawater Desalination 2.

Park, S. H., Park, Y. G., Lim, J. L., and Kim, S. (2015). Evaluation of Ceramic Membrane Applications for Water Treatment Plants with a Life Cycle Cost
Analysis. Desalination Water Treat. 54 (4-5), 973-979. doi:10.1080/ 19443994.2014.912162

Schlichter, B., Mavrov, V., and Chmiel, H. (2003). "Study of a Hybrid Process Combining Ozonation and Membrane Filtration-Filtration of Model Solutions. Desalination 156 (1-3), 257-265. doi:10.1016/S0011-9164(03) 00348-5

Simate, G. S., CluettMusapatika, J. E. T., Iyuke, S. E., Musapatika, E. T., Ndlovu, S., Walubita, L. F., et al. (2011). The Treatment of Brewery Wastewater for Reuse: State of the Art. Desalination 273 (2-3), 235-247. doi:10.1016/ j.desal.2011.02.035

Soltero, I. (2017). The Long Read: Do We Have the Technology for Potable Water Reuse? Available at: https://www.desalination.biz/desalination/the-long-readdo-we-have-the-technology-for-potable-water-reuse/.

Suárez, J., Villa, J., and Salgado, B. (2013). Experience with Integrated Ultrafiltration/Reverse Osmosis Systems in Industrial Applications in Spain. Desalination Water Treat. 51 (1-3), 423-431. doi:10.1080/ 19443994.2012.699344

Van der Bruggen, B., and Braeken, L. (2006). The Challenge of Zero Discharge: From Water Balance to Regeneration. Desalination 188 (1-3), 177-183. doi:10.1016/j.desal.2005.04.115

Vanoppen, M., Blandin, G., Derese, S., Le Clech, P., Post, J., and Verliefde, A. R. D. (2016). "Salinity Gradient Power and Desalination." In Sustainable Energy From Salinity Gradients. Elsevier, 281-313. doi:10.1016/b978-0-08-100312-1.00009-2

Werkneh, A. A., Beyene, H. D., and Osunkunle, A. A. (2019). Recent Advances in Brewery Wastewater Treatment; Approaches for Water Reuse and Energy Recovery: A Review. Environ. Sustainability 2 (2), 199-209. doi:10.1007/ s42398-019-00056-2

Xing, W., Fan, Y., and Jin, W. (2013). in Functional Nanostructured Materials and Membranes for Water Treatment. Editors Mikel. Duke, Dongyuan. Zhao, and Raphael. Semiat (Boschstr. 12, 69469 Weinheim, Germany All: Wiley-VCH Verlag \& Co. KGaA). doi:10.1002/9783527668502

Yonekawa, H., Tomita, Y., and Watanabe, Y. (2004). Behavior of Micro-particles in Monolith Ceramic Membrane Filtration with Pre-coagulation. Water Sci. Technology 50 (12), 317-325. doi:10.2166/wst.2004.0729

Zhang, X., Chen, Y., Konsowa, A. H., Zhu, X., and Crittenden, J. C. (2009). Evaluation of an Innovative Polyvinyl Chloride (PVC) Ultrafiltration Membrane for Wastewater Treatment. Separation Purif. Technology 70 (1), 71-78. doi:10.1016/j.seppur.2009.08.019

Conflict of Interest: Authors MT, YA, JA, FR and VM are employed by Aqualia; PL and JC are employed by Mahou San Miguel; AR is employed by Rood Wit Blauw Water.

Publisher's Note: All claims expressed in this article are solely those of the authors and do not necessarily represent those of their affiliated organizations, or those of the publisher, the editors and the reviewers. Any product that may be evaluated in this article, or claim that may be made by its manufacturer, is not guaranteed or endorsed by the publisher.

Copyright $\odot 2021$ Toran, Labrador, Ciriza, Asensio, Reigersman, Arevalo, Rogalla and Monsalvo. This is an open-access article distributed under the terms of the Creative Commons Attribution License (CC BY). The use, distribution or reproduction in other forums is permitted, provided the original author $(s)$ and the copyright owner(s) are credited and that the original publication in this journal is cited, in accordance with accepted academic practice. No use, distribution or reproduction is permitted which does not comply with these terms. 